\title{
OPEN Multiscale analysis of the hydrate based carbon capture from gas mixtures containing carbon dioxide
}

\author{
Xuebing Zhou ${ }^{1}$, Xiaoya Zang ${ }^{2}$, Zhen Long ${ }^{3}$ \& Deqing Liang ${ }^{4 凶}$
}

To reveal the kinetic performance of gas molecules in hydrate growth, hydrate formation from pure $\mathrm{CO}_{2}$, flue gas, and biogas was measured using in-situ Raman and macroscopic methods at $271.6 \mathrm{~K}$. In the in-situ Raman measurements, Raman peaks of gases in the hydrate phase were characterised and normalised by taking the water bands from 2800 to $3800 \mathrm{~cm}^{-1}$ as a reference, whose line shapes were not found to have a noticeable change in the conversion from Ih ice to $\mathrm{sl}$ hydrate. The hydrate growth was suggested to start with the formation of unsaturated hydrate nuclei followed by gas adsorption. In hydrate formed from all tested gases, $\mathrm{CO}_{2}$ concentrations in hydrate nuclei were found to be $23-33 \%$ of the saturation state. In the flue gas system, the $\mathrm{N}_{2}$ concentration reached a saturation state once hydrate nuclei formed. In the biogas system, competitive adsorption of $\mathrm{CH}_{4}$ and $\mathrm{CO}_{2}$ molecules was observed, while $\mathrm{N}_{2}$ molecules hardly evolved in hydrate formation. Combined with micro- and macroscopic analysis, small molecules such as $\mathrm{N}_{2}$ and $\mathrm{CO}_{2}$ were suggested to be more active in the formation of hydrate nuclei, and the preferential adsorption of $\mathrm{CO}_{2}$ molecules took place in the subsequent gas adsorption process.

Gas hydrates are ice-like crystalline minerals where gas molecules are trapped in the hydrogen-bonded network with distinct polyhedral water cages, and they typically form at ambient temperature and moderate pressure ${ }^{1}$. Gas hydrates have gained global attention as a potential energy source owing to their wide distribution in the permafrost and ocean floor ${ }^{2}$. They have also been considered as eco-friendly and energy-saving materials for carbon capture and sequestration (CCS $)^{3}$. In this case, understanding the kinetic properties of gas hydrates is essential to the successful applications of gas production from hydrate-bearing deposits and CCS technologies.

The preferential incorporation of $\mathrm{CO}_{2}$ in hydrate formation from gas mixtures is key to hydrate-based CCS technologies. Usually, the gas mixtures containing $\mathrm{CO}_{2}$ form typical sI hydrates, which include six tetrakaidecahedron $\left(5^{12} 6^{2}\right)$ cages and two pentagonal dodecahedron $\left(5^{12}\right)$ cages per unit cell. Structural analysis has revealed that high gas occupancies in the large $\left(5^{12} 6^{2}\right)$ cages are important for stabilising sI hydrate ${ }^{4,5} \cdot \mathrm{CO}_{2}$ molecules have a size capable of supporting the $5^{12} 6^{2}$ cage structure, while $\mathrm{N}_{2}, \mathrm{CH}_{4}$, and $\mathrm{H}_{2}$ molecules are all slightly too small ${ }^{6-8}$. This allows $\mathrm{CO}_{2}$ molecules to be enriched in the hydrate phase. Gas hydrates are thus proposed to adsorb $\mathrm{CO}_{2}$ from flue gas $\left(\mathrm{N}_{2} / \mathrm{CO}_{2}\right)$, precombustion gas $\left(\mathrm{H}_{2} / \mathrm{CO}_{2}\right)$ from integrated gasification combined cycles, or contaminated natural gas $\left(\mathrm{CH}_{4} / \mathrm{CO}_{2}\right)$ in power plants ${ }^{9-11}$.

Based on thermodynamic analysis, investigations of hydrate-based carbon capture have been divided into three methodological categories. The first is the enhancement of the separation efficiency by lowering the stability of formed hydrates. In harsh environments, more $\mathrm{CO}_{2}$ molecules are adsorbed in the hydrate phase to increase hydrate stability. Therefore, increasing the temperature or adding solutes such as inorganic salts are common methods of enhancing the selectivity of formed hydrates ${ }^{12,13}$. The second method is to allow hydrate to form at milder running conditions during crystallisation. Hydrate promoters such as tetrahydrofuran and ionic salts allow hydrates to form at about $275 \mathrm{~K}$ and atmospheric pressure ${ }^{14-16}$. The last method is to strengthen the gas adsorption rate of the hydrates. Hydrate formation on porous materials or in stirring reactors is proposed to enlarge the gas-liquid interface and reduce the gas diffusion resistance in the liquid phase $\mathrm{e}^{8,10}$.

Although gas separation efficiency is frequently emphasised, in the kinetic mechanism of hydrate growth, the diffusion and distribution of gas and water molecules does not receive equivalent focus, especially at the microscopic level. The micro-kinetic description of the preferential incorporation of $\mathrm{CO}_{2}$ in hydrate growth is typically obtained from macroscopic measurements and analysed by thermodynamic theory, but not fully

${ }^{1}$ Guangzhou Institute of Energy Conversion, Chinese Academy of Sciences, Guangzhou 510640, China. ${ }^{2}$ CAS Key Laboratory of Gas Hydrate, Guangzhou 510640, China. ${ }^{3}$ Guangdong Provincial Key Laboratory of New and Renewable Energy Research and Development, Guangzhou 510640, China. ${ }^{4}$ State Key Laboratory of Natural Gas Hydrate, Beijing 100028, China. ${ }^{\varpi}$ email: liangdq@ms.giec.ac.cn 


\begin{tabular}{|l|l|l|l|l|l|}
\hline & & & \multicolumn{4}{|c|}{$\begin{array}{l}\text { Feed gas composition } \\
(\mathbf{m o l} \%)\end{array}$} \\
\cline { 4 - 6 } Starting material & Temperature (K) & Pressure $(\mathbf{M P a})$ & $\mathbf{C O}_{\mathbf{2}}$ & $\mathbf{N}_{\mathbf{2}}$ & $\mathbf{C H}_{\mathbf{4}}$ \\
\hline Ih ice & $271.6 \pm 0.1$ & $2.1 \pm 0.15$ & 99.9 & - & - \\
\hline Ih ice & $271.6 \pm 0.1$ & $6.1 \pm 0.15$ & $20 \pm 0.1$ & $80 \pm 0.1$ & - \\
\hline Ih ice & $271.6 \pm 0.1$ & $2.7 \pm 0.15$ & $40 \pm 0.1$ & $10 \pm 0.1$ & $50 \pm 0.1$ \\
\hline
\end{tabular}

Table 1. Initial conditions of in situ Raman measurements.

verified at the microscopic level ${ }^{3}$. Because experiments on hydrate-based carbon capture are generally carried out in gas-liquid-hydrate systems, hydrate growth rates are estimated by calculating accumulated gas consumption without considering gas dissolution and the increasing hydrate nuclei, which may greatly affect hydrate formation ${ }^{17,18}$. In addition, molecular simulations and microscopic experiments have indicated that small gas molecules are active in hydrate formation ${ }^{19,20}$.

The major difficulties in measuring the micro-kinetics of hydrate growth are the growing hydrate surface and the determination of the gas molecules in the hydrate and liquid phases. Common methods allow hydrate particles to nucleate in the liquid phase, where the newly formed hydrate layer may quickly cover the original layer as the hydrate grows larger, inhibiting continuous tracking at a specific spot in the hydrate phase $\mathrm{e}^{21,22}$. Meanwhile, high fluidity and adhesion may also change the growth pattern of hydrate particles. To overcome difficulties, ice has been chosen as a starting material because of its limited fluidity ${ }^{23,24}$. By observing the growth of hydrate on ice particles, Falenty et al. ${ }^{25}$ found that the newly formed hydrate layer grew outwards only by a few micrometres. These previous studies indicate that ice could be an ideal material for investigate the microkinetics of hydrate growth.

Therefore, in this study, hydrate formation from ice powder was measured in situ by Raman spectroscopy at $271.6 \mathrm{~K}$. A simple method was proposed to characterise the growth of gas concentration in the hydrate phase. Synthesised flue gas, biogas, and pure $\mathrm{CO}_{2}$ were used to compare the gas adsorption rates of $\mathrm{CH}_{4}, \mathrm{CO}_{2}$, and $\mathrm{N}_{2}$ by hydrates. To verify the hydrate growth from the gas mixtures, macroscopic measurements were also performed under the same operating conditions as those in the Raman measurements (Table 1). The kinetics of hydrate formation were characterised according to gas enrichment in the hydrate phase. The preferential incorporation of gas molecules in different stages of hydrate formation was described quantitatively. The results provide a microscopic insight into the hydrate growth in the initial stage of hydrate growth, especially from gas mixtures.

\section{Results}

Identification of characteristic spectra. When the Raman laser focused on the hydrate surface, Raman peaks of gas molecules in both the gas and hydrate phases were observed, as shown in Fig. 1. The positions of the characteristic peaks of gases agreed well with the reference ${ }^{26,27}$. It should be noted that the Raman peak of gaseous $\mathrm{CH}_{4}$ at $2919 \mathrm{~cm}^{-1}$ overlapped with the peak of $\mathrm{CH}_{4}$ in the small cages of sI hydrates, which could not be clearly identified. Such a phenomenon could also be seen in the characteristic peaks of $\mathrm{N}_{2}$ molecules in the hydrate and gas phases. However, they could still be separated by the fitting curves, as shown in Figure S1. The peak of $\mathrm{CH}_{4}$ in the small cages of sI hydrates at $2916 \mathrm{~cm}^{-1}$ could be separated by fitting the peak at $2919 \mathrm{~cm}^{-1}$, while the peak of $\mathrm{N}_{2}$ in sI hydrates at $2324 \mathrm{~cm}^{-1}$ could be observed by fitting the peak at $2330 \mathrm{~cm}^{-1}$. In addition, no evident split was found to indicate the specific distributions of $\mathrm{CO}_{2}$ and $\mathrm{N}_{2}$ in the hydrate phase such that $\mathrm{CO}_{2}$ and $\mathrm{N}_{2}$ molecules in large and small cages could not be distinguished from the spectra ${ }^{17}$.

The Raman spectra of the O-H stretching modes of water molecules in Ih ice and sI hydrate are shown in Figure S1. Typically, the water band ranging from 2800 to $3800 \mathrm{~cm}^{-1}$ corresponds to symmetric and antisymmetric stretching vibrational modes of water molecules, accompanied by additional contributions from the Fermi resonance caused by the overlap of the $\mathrm{O}-\mathrm{H}$ stretching mode frequency and the $\mathrm{O}-\mathrm{H}$ bending overtone mode ${ }^{28}$. However, theoretical analysis revealed that the $\mathrm{O}-\mathrm{H}$ stretching mode spectra of ice Ih were strongly affected by the vibrational modes coupled in a complex manner ${ }^{29}$. The spectral features in Ih ice were mainly determined by the large intermolecular couplings and diagonal disorder rather than intramolecular couplings ${ }^{30-32}$. By relating the frequency distributions to the spectra, four subpeaks could be observed, as shown in Figure S1. Interestingly, the shape of the water band did not noticeable change as Ih ice transformed into sI hydrate. In both Ih ice and sI hydrate, each water molecule was hydrogen-bonded to the four nearest neighbours in a tetrahedral arrangement, and the average $\mathrm{H}-\mathrm{O}-\mathrm{H}$ angle only departed a few degrees from the tetrahedral angle ${ }^{33}$. Therefore, the influence of the structural change from Ih ice to sI hydrate on the shape of the water bands was quite limited. Combining with the fact that the integrated peak intensities of gas and water molecules were proportional to their molar fractions in the hydrate phase ${ }^{17,34}$, quantitative descriptions of the gas concentrations in the hydrate phase were calculated by dividing the peak area of gases by the area of the water band.

Hydrate formation from pure $\mathrm{CO}_{2}$. Figure 2(a) shows the in situ Raman spectra of hydrate formation from pure $\mathrm{CO}_{2}$ at $271.6 \mathrm{~K}$ and $2.7 \mathrm{MPa}$. The peaks of gaseous $\mathrm{CO}_{2}$ remained almost constant through $120 \mathrm{~min}$, while the peaks representing $\mathrm{CO}_{2}$ in the hydrate phase grew quickly in the initial $60 \mathrm{~min}$ and then gradually reached stability. This type of growth pattern was consistent with the previous observations and further indicated that the conversion from Ih ice to gas-saturated sI hydrate was a gradual process rather than an abrupt change $\mathrm{e}^{21,23,35}$. 


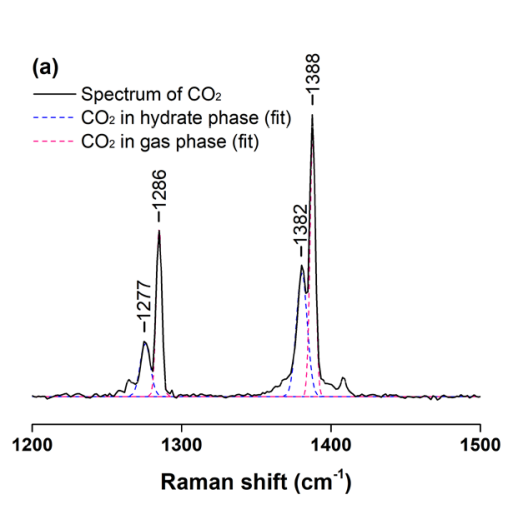

(b)

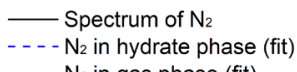

-..- $\mathrm{N}_{2}$ in gas phase (fit)
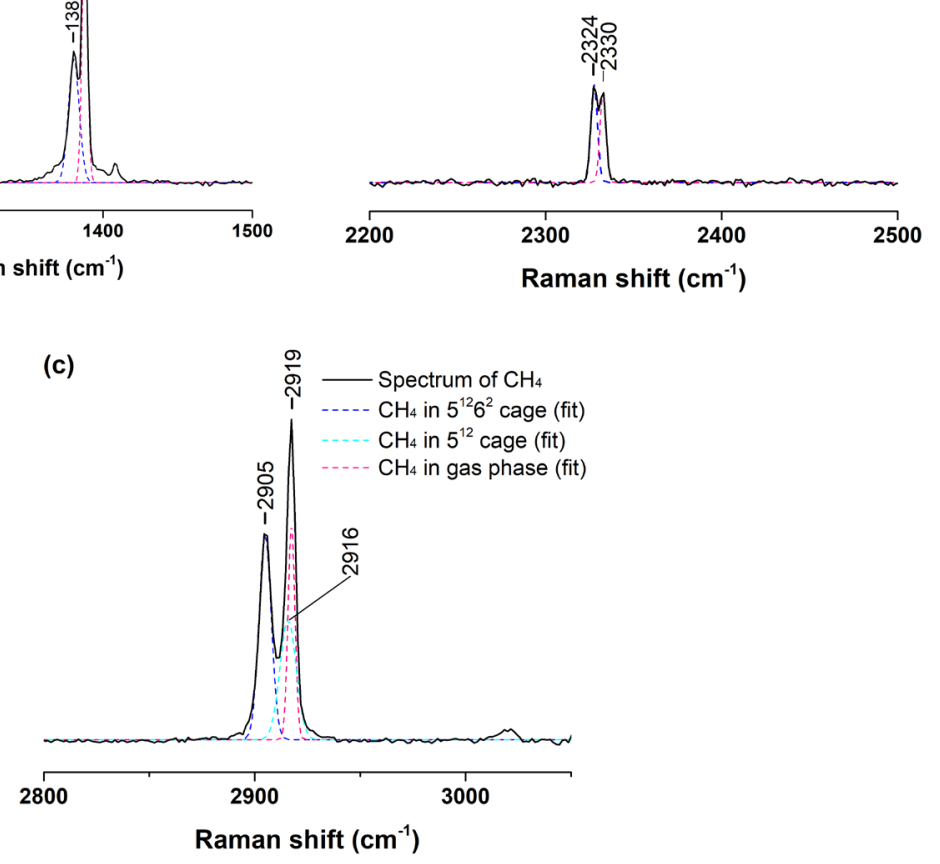

Figure 1. Typical spectra of $\mathrm{CO}_{2}, \mathrm{~N}_{2}$, and $\mathrm{CH}_{4}$ observed from in situ Raman measurements at 271.6 K. The characteristic peaks of $\mathrm{CO}_{2}, \mathrm{~N}_{2}$, and $\mathrm{CH}_{4}$ molecules in gas and hydrate phase are marked by dashed lines.
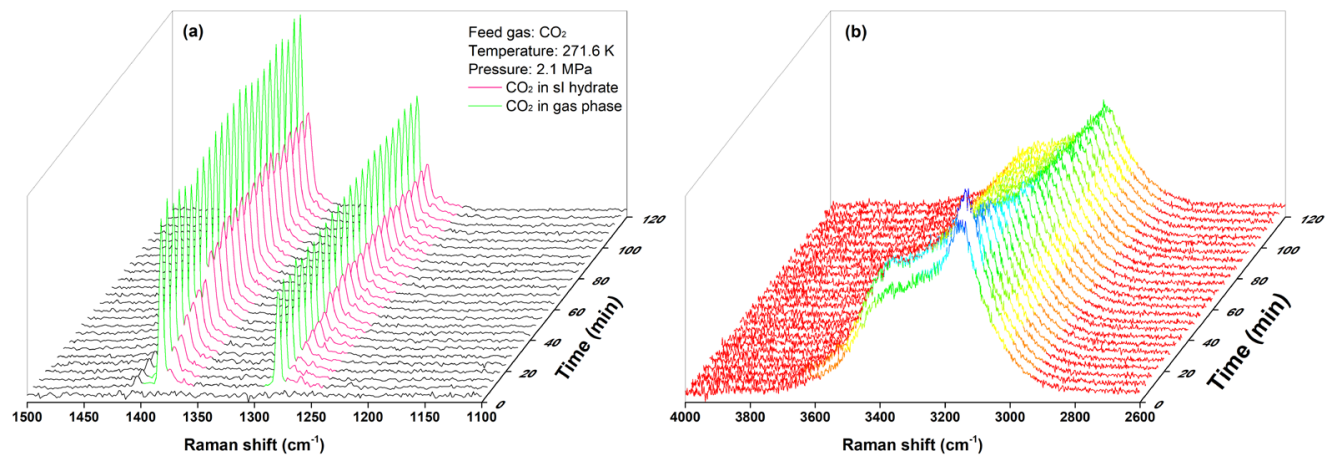

Figure 2. In situ Raman spectra of hydrate formation from pure $\mathrm{CO}_{2}$. (a) Peaks of $\mathrm{CO}_{2}$ molecules in hydrate and gas phase, (b) corresponding change of water band with colour mapping along intensity values.

Another observed phenomenon was the gradual decrease in the intensities of the water bands, as seen in Fig. 2(b). In most of our experiments, the intensities of the water bands reduced by at least $20 \%$ of the initial values. The shift of the sample surface in the measurement could be the primary reason for this observation. Although the densities of Ih ice and sI hydrate did not deviate significantly, hydrate formation from Ih ice was still found to go through a volume increase associated with hydrate expansion ${ }^{25}$. Therefore, the laser spot originally focused on the sample surface was gradually embedded in the growing surface, which led to reductions in the peak intensities.

Profiles of the normalised intensity of $\mathrm{CO}_{2}$ in the hydrate phase are shown in Fig. 3. The profiles were found to follow a similar trend and gradually reached a stable value of approximately 0.029 , indicating good repeatability of the experiment. The growth patterns of hydrate at each spot on the ice surface were generally the same. The normalised intensity of the encaged $\mathrm{CO}_{2}$ jumped to 0.009 at $5 \mathrm{~min}$, which was $33 \%$ of the saturation state, and then increased gradually (Fig. 3). Structural conversion from Ih ice to sI hydrate was thought to take place once the gas was injected ${ }^{25}$. However, the newly formed hydrate nuclei seemed unsaturated with gas molecules. In other words, the water molecules formed the water lattice of sI hydrate first, and then the unsaturated hydrate 


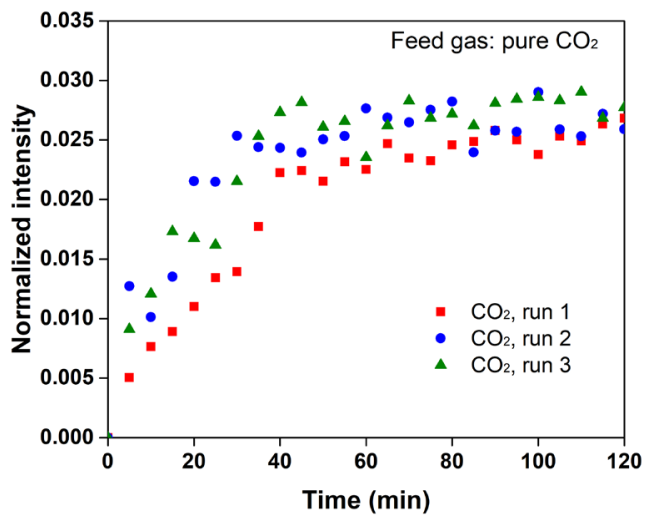

Figure 3. Growth of the normalized intensities of $\mathrm{CO}_{2}$ in the hydrate phase with time. Runs 1-3 are repeated tests performed at the same experimental conditions.

structure was stabilised via continuous gas adsorption. Another possible explanation for this increase was that the Ih ice at the measuring spots was not fully converted into hydrate. However, the thickness of the formed hydrate film was at least $2 \mu \mathrm{m}$, which is larger than the size of the measuring spot, according to previous studies ${ }^{23}$. In this case, the newly formed hydrates were assumed to be in an unsaturated and unstable state. They continuously adsorbed gas molecules until a stable state was reached.

The gas saturation at hydrate nucleation has not been well understood. Newly formed hydrate nuclei are usually assumed to be in an equilibrium state in classical nucleation theory ${ }^{9,11}$. Simulation results have also indicated that the cage occupancies of gases in the newly formed hydrate layer have to reach $90 \%$ to guarantee the stability of the hydrate structure ${ }^{8,36}$. However, most of these tests allowed hydrates to grow in liquid water where water molecules were mobile and abundant. More importantly, the structural order of the water lattice can be easily changed in liquid water, especially with the help of gas molecules. In the conversion from ice to hydrate, most of the water molecules were hydrogen-bonded in a tetrahedral arrangement. As gas molecules penetrated into the Ih ice phase, the structural type was not easily changed to accommodate gas molecules while keeping the water molecules tetrahedrally hydrogen-bonded. The slow gas diffusion was also limited by the gas concentration at the recrystallization front of water molecules. The unsaturated hydrate phase, which was stabilised by only a few gas molecules, was therefore formed at the beginning of hydrate growth ${ }^{37,38}$. In this case, hydrate formation from Ih ice could be viewed as a formation of hydrate nuclei followed by continuous gas adsorption.

Hydrate formation from synthesized flue gas. In the hydrate formation from the synthesised flue gas, the growth pattern of the $\mathrm{CO}_{2}$ peaks representing the encaged $\mathrm{CO}_{2}$ was generally the same as that in $\mathrm{CO}_{2}$ hydrate growth, as seen in Figure S2. Characteristic peaks of $\mathrm{CO}_{2}$ in the sI hydrate phase were found at 5 min, verifying the importance of $\mathrm{CO}_{2}$ molecules in the structural determination and stabilisation of the formed hydrates. The characteristic peaks of the encaged $\mathrm{N}_{2}$ could not be directly observed from the in situ spectra due to the high overlap of the Raman peaks of gaseous and encaged $\mathrm{N}_{2}$ molecules. To quantitatively analyse the $\mathrm{N}_{2}$ concentration in the hydrate phase, the peaks of $\mathrm{N}_{2}$ in sI hydrates at $2324 \mathrm{~cm}^{-1}$ were separated by the fitting curves, as previously mentioned.

The growth patterns of the normalised intensities of $\mathrm{CO}_{2}$ and $\mathrm{N}_{2}$ molecules in the hydrate cell were different. In the formation of hydrate nuclei, the normalised intensity of $\mathrm{CO}_{2}$ in the hydrate phase jumped to 0.003 at 5 min, which was about $30 \%$ of the saturation state, and then increased gradually. The normalised intensity of $\mathrm{N}_{2}$ also jumped to approximately 0.003 at the start of hydrate growth but remained stable thereafter, as seen in Figure S3. In the synthesised flue gas where $\mathrm{N}_{2}$ was abundant, a considerable amount of gas molecules was assumed to be required after the formation of the unsaturated hydrate structure. However, the $\mathrm{N}_{2}$ concentration in the hydrate phase reached saturation once the hydrate crystallised, suggesting that $\mathrm{N}_{2}$ molecules were more active than $\mathrm{CO}_{2}$ in the formation of hydrate nuclei. This may be closely related to the small size of $\mathrm{N}_{2}$ molecules, which are weak in cage stabilisation but strong in cage penetration ${ }^{19,36}$. As for $\mathrm{CO}_{2}$, the presence of $\mathrm{CO}_{2}$ prevented $\mathrm{N}_{2}$ to form sII hydrate and allowed the hydrate growth to take place at lower pressure so that the enrichment of $\mathrm{CO}_{2}$ in the hydrate phase followed the subsequent gas adsorption process ${ }^{17,39}$.

Figure 4 shows the preferential incorporation of $\mathrm{N}_{2}$ molecules in the initial stage. The ratio of the normalized intensities of $\mathrm{N}_{2}$ and $\mathrm{CO}_{2}$ declined continuously from about 1.7-0.6 in the first $30 \mathrm{~min}$. It should be noted that the ratio of the normalized intensities of $\mathrm{N}_{2}$ and $\mathrm{CO}_{2}$ did not reflect the absolute concentration ratio of $\mathrm{N}_{2}$ and $\mathrm{CO}_{2}$ in the hydrate phase, but it indicated the concentration growth of $\mathrm{CO}_{2}$ in the hydrate phase was more evident than that of $\mathrm{N}_{2}$ during hydrate crystallization. Since the $\mathrm{N}_{2}$ concentration in the hydrate phase had already reached saturation in the formation of hydrate nuclei, the decrease of the ratio of the normalized intensities of $\mathrm{N}_{2}$ to $\mathrm{CO}_{2}$ does not mean that the increase of $\mathrm{N}_{2}$ concentration in the hydrate phase was slower than that of $\mathrm{CO}_{2}$. On the contrary, the slow adsorption of $\mathrm{CO}_{2}$ is suggested to be a rate-limiting step ${ }^{19}$. From another perspective, the abundance of $\mathrm{N}_{2}$ molecules in newly formed hydrate nuclei increased the ratio and resulted in the evident decrease in the ratio during gas adsorption. In this case, $\mathrm{N}_{2}$ molecules were essential to the formation of hydrate nuclei. 


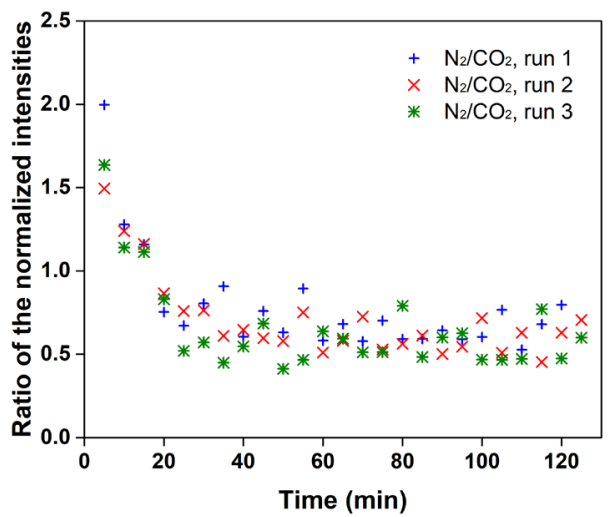

Figure 4. The ratio of the normalized intensities of $\mathrm{N}_{2}$ and $\mathrm{CO}_{2}$ molecules in hydrate formation from synthesized flue gas.
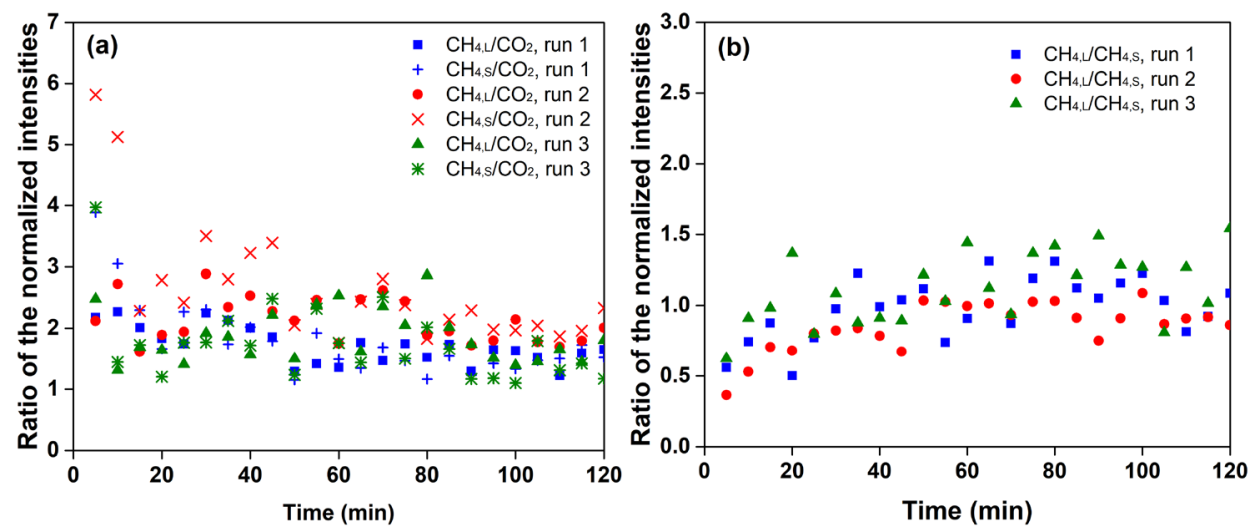

Figure 5. The ratio of the normalized intensities of $\mathrm{CH}_{4}$ and $\mathrm{CO}_{2}$ molecules and the $\mathrm{CH}_{4}$ in the large and small cages in hydrate formation from synthesized biogas. The normalized intensities of $\mathrm{CH}_{4}$ in large and small cages are labelled as $\mathrm{CH}_{4, \mathrm{~L}}$ and $\mathrm{CH}_{4, \mathrm{~S}}$, respectively.

Hydrate formation from synthesized biogas. In the hydrate formation from synthesised biogas, the kinetic properties of $\mathrm{CO}_{2}$ during cage filling were also found to be less efficient than those of $\mathrm{CH}_{4} \mathrm{molecules}_{\text {. The }}$ $\mathrm{N}_{2}$ peaks were greatly reduced because of the low $\mathrm{N}_{2}$ composition in the feed gas (Figure S4), and the characteristic peaks of the encaged $\mathrm{N}_{2}$ molecules were difficult to separate by the fitting curves so that the amount of $\mathrm{N}_{2}$ molecules in the hydrate phase was negligible. The growth patterns of the Raman peaks of $\mathrm{CO}_{2}$ and $\mathrm{CH}_{4}$ in the hydrate phase were generally the same. The competitive incorporation of gas molecules for hydrate growth was therefore thought to occur between $\mathrm{CH}_{4}$ and $\mathrm{CO}_{2}$.

In contrast to the characteristic peak of $\mathrm{N}_{2}$ in the hydrate phase, the peaks of $\mathrm{CH}_{4}$ in the large $\left(5^{12} 6^{2}\right)$ and small $\left(5^{12}\right)$ cages could be distinguished in the spectra. A more specific distribution of $\mathrm{CH}_{4}$ in the hydrate phase was thus obtained, as shown in Figure S5. At 5 min, the normalised intensities of $\mathrm{CH}_{4}$ in the large and small cages jumped to 0.003 and 0.006 , which were approximately $29 \%$ and $65 \%$ of the saturation state, respectively. The $\mathrm{CH}_{4}$ concentrations in the small cages were two times higher than those in the large cages at the start of hydrate growth. $\mathrm{CH}_{4}$ molecules were preferably adsorbed in the small cages because of their suitable molecular size $\mathrm{e}^{6,8}$, but were replaced by $\mathrm{CO}_{2}$ molecules in the large cages.

The competitive occupation between $\mathrm{CH}_{4}$ and $\mathrm{CO}_{2}$ was found to behave differently during hydrate formation. When hydrate nuclei were newly formed on the ice surface, the normalised intensity of $\mathrm{CO}_{2}$ in the hydrate phase was 0.001 at $5 \mathrm{~min}$, which was approximately $23 \%$ of the saturation state, as shown in Figure S5. Compared with hydrate formation from pure $\mathrm{CO}_{2}$ and synthesised flue gas, the initial normalised intensities of $\mathrm{CO}_{2}$ in the hydrate phase were found to decrease from 33 to $23 \%$ of their values at the saturation state. In addition, the ratio of the normalised intensities of $\mathrm{CH}_{4}$ and $\mathrm{CO}_{2}$ was decreasing as seen in Fig. 5(a). $\mathrm{N}_{2}$ and $\mathrm{CH}_{4}$ molecules were thought to exhibit growing importance in stabilising the unsaturated hydrate structure at the beginning of hydrate formation, and $\mathrm{CH}_{4}$ molecules performed better than $\mathrm{N}_{2}$ molecules.

During hydrate growth, the normalised intensities of $\mathrm{CH}_{4}$ in the large and small cages continued to grow, and the ratio of these intensities was found to increase from approximately $0.5-1.2$, as seen in Fig. 5(b). Since two thirds of the $\mathrm{CH}_{4}$ molecules were incorporated in the small cages at the beginning of hydrate formation, $\mathrm{CH}_{4}$ molecules appear to be important in stabilising the small cages of the hydrate nuclei. However, in the subsequent 

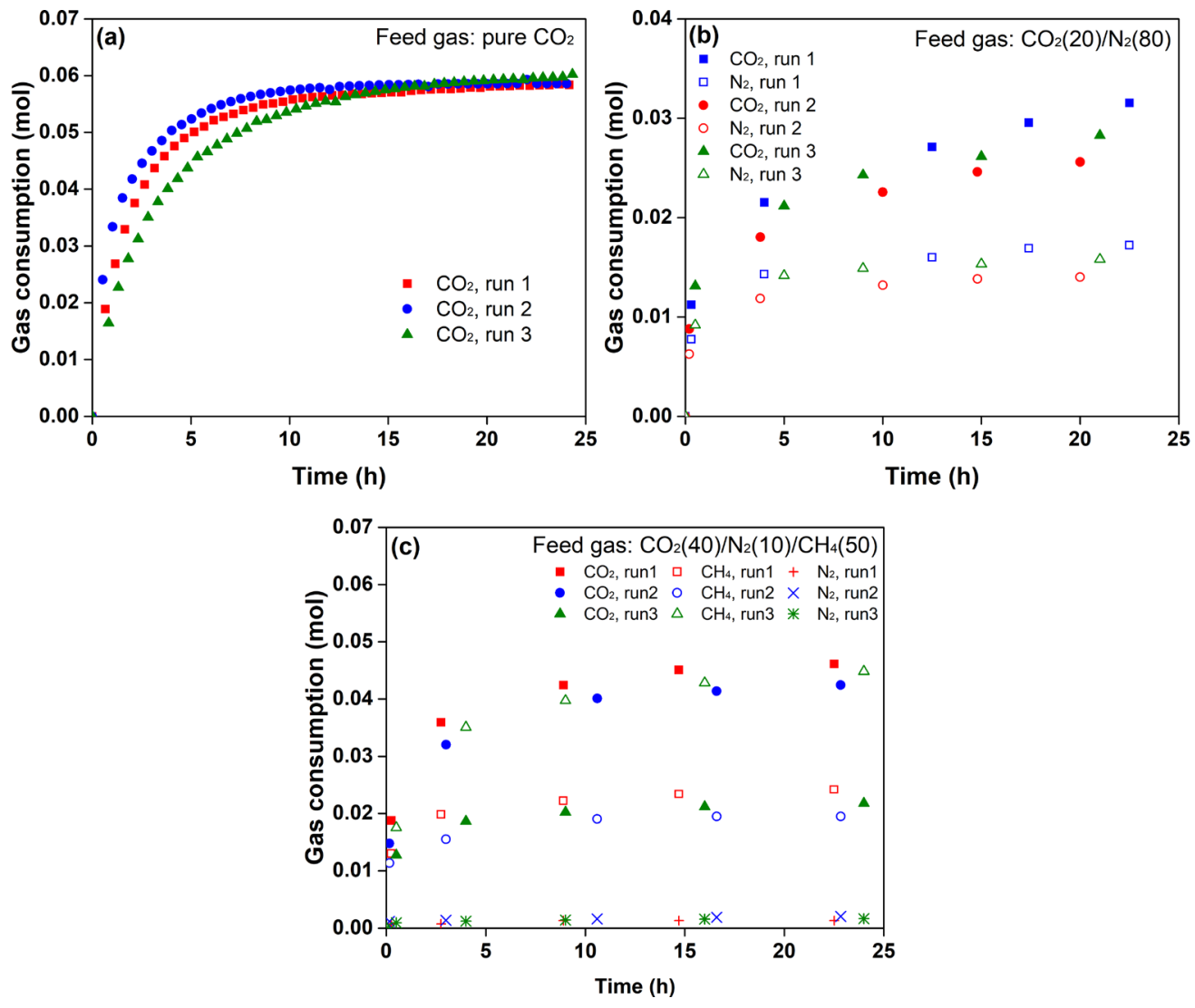

Figure 6. Profiles of the accumulated gas consumption in hydrate formation from (a) pure $\mathrm{CO}_{2}$, (b) flue gas, and (c) biogas.

gas adsorption period, the growth rates of $\mathrm{CH}_{4}$ in the large cages were higher than those in the small cages, indicating that the difficulty of $\mathrm{CH}_{4}$ entering the small cages was higher than that in the large cages.

In the subsequent gas adsorption period, the concentrations of both $\mathrm{CH}_{4}$ and $\mathrm{CO}_{2}$ continued to grow, which is known as a competitive cage occupation process ${ }^{40}$. The ratio of $\mathrm{CH}_{4}$ and $\mathrm{CO}_{2}$ in large cages decreased slowly from approximately 2.3-1.8, while the ratio of $\mathrm{CH}_{4}$ and $\mathrm{CO}_{2}$ in the small cages dropped from approximately 4.6-2.5 within $30 \mathrm{~min}$, as shown in Figure S4. The $\mathrm{CO}_{2}$ concentration in the hydrate phase were posited to be grow faster than the $\mathrm{CH}_{4}$ concentration in both large and small cages, which was in accordance with the previous conclusion that $\mathrm{CO}_{2}$ molecules were preferentially incorporated in the formation of mixed $\mathrm{CH}_{4}-\mathrm{CO}_{2}$ hydrates ${ }^{40}$.

Based on the above analysis, two kinetic stages could be distinguished in the hydrate formation from Ih ice. The first stage was the formation of unsaturated hydrate nuclei, which were completed within the initial 5 min of in situ Raman measurements. The second stage was the continuous adsorption of gas molecules, which was evident from the growth of the normalised intensities of gas molecules in the hydrate phase. However, the enrichment of gas molecules in the first stage was found to be different in this study. $\mathrm{CO}_{2}$ molecules did not occupy most of the cages in the hydrate nuclei. Instead, small molecules such as $\mathrm{N}_{2}$ and $\mathrm{CH}_{4}$ behaved more actively than $\mathrm{CO}_{2}$ during the formation of hydrate nuclei. While the mechanism of this phenomenon remains unclear, the results revealed the importance of small gas molecules in hydrate formation from gas mixtures.

Macroscopic measurements. Figure 6 shows the gas consumption during $25 \mathrm{~h}$ of hydrate formation. The repeated tests indicated that the results from each experiment had good consistency. In the hydrate formation from pure $\mathrm{CO}_{2}$, the $\mathrm{CO}_{2}$ consumption profiles were generally the same as the growth pattern of the normalised integrated intensities of $\mathrm{CO}_{2}$ in Raman measurements. In the initial $12 \mathrm{~h}$, the accumulated $\mathrm{CO}_{2}$ consumption grew quickly, and the gas consumption rate was assumed to be primarily limited by the hydrate growth on the surface of the ice powder ${ }^{3}$. After the initial $12 \mathrm{~h}, \mathrm{CO}_{2}$ consumption slowed over time, although the accumulated $\mathrm{CO}_{2}$ consumption was approximately $0.059 \mathrm{~mol}$, which was far less than the amount of $\mathrm{CO}_{2}$ required for the complete conversion of ice into hydrate $(0.179 \mathrm{~mol})$. Therefore, the gas consumption after $12 \mathrm{~h}$ was largely limited by the gas diffusion in the hydrate phase. Similar to the sharp increase in the normalised intensity of the encaged $\mathrm{CO}_{2}$ at $5 \mathrm{~min}$, the $\mathrm{CO}_{2}$ consumption also jumped to approximately $0.02 \mathrm{~mol}$ at $30 \mathrm{~min}$. The formation of hydrate nuclei was assumed to occur once the pressure surpassed the equilibrium pressure of $\mathrm{CO}_{2}$ hydrate.

In the hydrate formation from flue gas, a sharp increase in $\mathrm{CO}_{2}$ and $\mathrm{N}_{2}$ consumption at 30 min could also be observed. Then, $\mathrm{CO}_{2}$ was consumed almost linearly with time while $\mathrm{N}_{2}$ consumption grew much slower. The ratio of $\mathrm{N}_{2}$ to $\mathrm{CO}_{2}$ consumption decreased from 0.70 to 0.55 (Fig. 7), suggesting a strong demand for $\mathrm{CO}_{2}$ in hydrate 

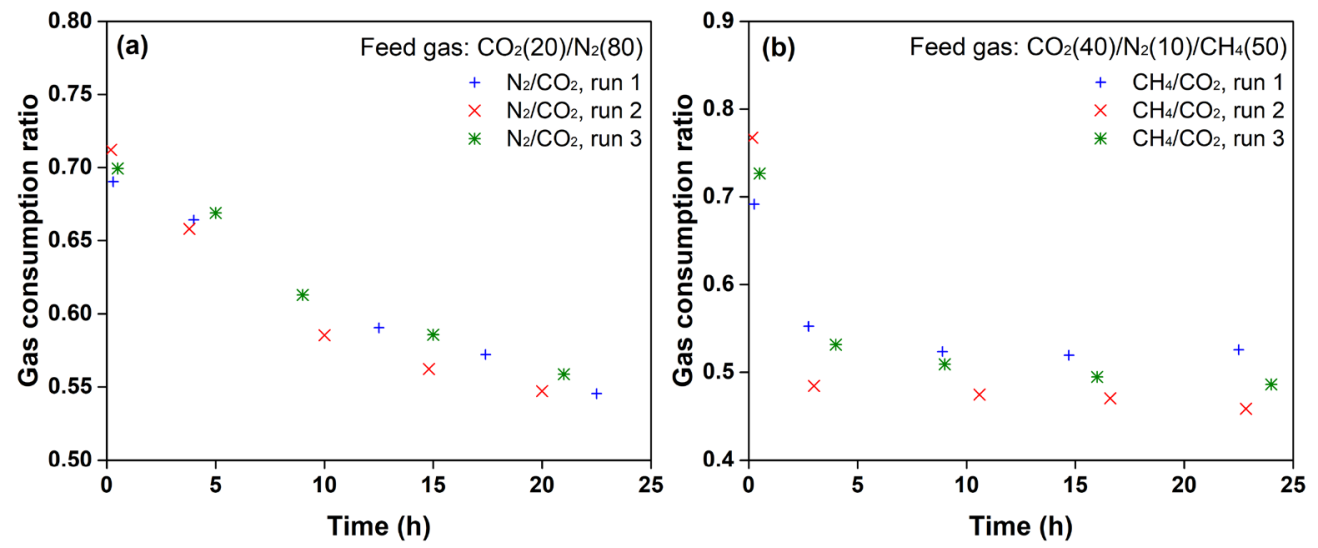

Figure 7. The gas consumption ratio of $\mathrm{N}_{2}$ to $\mathrm{CO}_{2}$ and $\mathrm{CH}_{4}$ to $\mathrm{CO}_{2}$ in the hydrate formation from flue gas and biogas, respectively.

growth. It also indicated that $\mathrm{N}_{2}$ molecules were more active than $\mathrm{CO}_{2}$ molecules in the formation of hydrate nuclei, which is consistent with the conclusion obtained from in situ Raman measurements.

In the hydrate formation from biogas, $\mathrm{N}_{2}$ molecules were shown to be less involved in hydrate growth, as seen in Fig. 6(c). Competitive adsorption of $\mathrm{CH}_{4}$ and $\mathrm{CO}_{2}$ dominated hydrate growth. The amount of $\mathrm{CO}_{2}$ adsorbed was twice that of $\mathrm{CH}_{4}$, although the mole percent of $\mathrm{CH}_{4}$ was relatively higher than that of $\mathrm{CO}_{2}$ in the feed gas. $\mathrm{CO}_{2}$ molecules were more preferentially adsorbed by the hydrates. However, $\mathrm{CH}_{4}$ molecules behaved more actively than $\mathrm{CO}_{2}$ molecules at the initial stage. The ratio of $\mathrm{CH}_{4}$ to $\mathrm{CO}_{2}$ was found to be around 0.73 , as seen in Fig. 7(b), suggesting that $\mathrm{CH}_{4}$ molecules also played a key role in promoting the nucleation of hydrates.

\section{Discussion}

To reveal the kinetic performance of gas molecules in hydrate growth, hydrate formation from pure $\mathrm{CO}_{2}$, flue gas, and biogas was measured by in situ Raman spectroscopy and a macroscopic method at $271.6 \mathrm{~K}$. Hydrate formation from Ih ice was found to initiate with hydrate nucleation followed by continuous gas adsorption. Gas molecules were found to have the same kinetic behaviour in both in situ Raman and macroscopic measurements. $\mathrm{CO}_{2}$ molecules were preferentially adsorbed in the hydrate phase. The gas concentrations in the hydrate phase were observed to have a sharp rise at $5 \mathrm{~min}$, and the initial normalised intensities of $\mathrm{CO}_{2}$ in the hydrate phase were $23-33 \%$ of their values at saturation states. In the subsequent process, $\mathrm{CO}_{2}$ adsorption was also more evident than that of $\mathrm{CH}_{4}$ and $\mathrm{N}_{2}$ molecules. However, $\mathrm{CH}_{4}$ and $\mathrm{N}_{2}$ molecules were more active in the initial stage of hydrate formation. The ratios of $\mathrm{N}_{2}$ to $\mathrm{CO}_{2}$ and $\mathrm{CH}_{4}$ to $\mathrm{CO}_{2}$ were found to decrease during hydrate growth in both in situ Raman and macroscopic measurements. In this case, small molecules such as $\mathrm{N}_{2}$ and $\mathrm{CO}_{2}$ were suggested to be more active in forming unsaturated hydrate nuclei, while the preferential incorporation of $\mathrm{CO}_{2}$ molecules took place in the subsequent gas adsorption process. In the following studies, we will focus on the effect of temperature and pressure on the selective absorption of hydrate at the initial stage of hydrate growth.

\section{Methods}

The hydrate formation from Ih ice were measured at $271.6 \mathrm{~K}$ using in situ Raman and macroscopic methods. In macroscopic measurements, hydrates were formed from ice powder which was densely packed in a cylinder shape. Gas samples were taken at regular time intervals as seen in Fig. 6 and analysed by a gas chromatography. In situ Raman measurements were performed in a high pressure optical reactor. The laser spot was fixed at the ice surface to obtain the spectral change from ice to hydrate. Information about the devices and procedures of was detailed in supporting information.

Received: 8 January 2021; Accepted: 6 April 2021

Published online: 28 April 2021

\section{References}

1. Kumar, K. V., Preuss, K., Titirici, M. M. \& Rodriguez-Reinoso, F. Nanoporous materials for the onboard storage of natural gas. Chem. Rev. 117, 1796-1825 (2017).

2. Huang, L., Su, Z., Wu, N. Y. \& Cheng, J. W. Analysis on geologic conditions affecting the performance of gas production from hydrate deposits. Mar. Petrol Geol. 77, 19-29 (2016).

3. Ma, Z. W., Zhang, P., Bao, H. S. \& Deng, S. Review of fundamental properties of $\mathrm{CO}_{2}$ hydrates and $\mathrm{CO}_{2}$ capture and separation using hydration method. Renew. Sust. Energ. Rev. 53, 1273-1302 (2016).

4. Ballenegger, V. Cage occupancies in nitrogen clathrate hydrates from Monte Carlo simulations. J. Phys. Chem. C 123, 16757-16765 (2019).

5. Das, S., Baghel, V. S., Roy, S. \& Kumar, R. A molecular dynamics study of model SI clathrate hydrates: The effect of guest size and guest-water interaction on decomposition kinetics. Phys. Chem. Chem. Phys. 17, 9509-9518 (2015). 
6. Lauricella, M. et al. Clathrate structure-type recognition: Application to hydrate nucleation and crystallisation. J. Chem. Phys. 142, 244503 (2015).

7. Zhou, X. B., Lin, F. H. \& Liang, D. Q. Multiscale analysis on $\mathrm{CH}_{4}-\mathrm{CO}_{2}$ swapping phenomenon occurred in hydrates. J. Phys. Chem. C 120, 25668-25677 (2016).

8. Papadimitriou, N. I., Tsimpanogiannis, I. N., Economou, I. G. \& Stubos, A. K. Monte Carlo simulations of the separation of a binary gas mixture (CH4 + CO2) using hydrates. Phys. Chem. Chem. Phys. 20, 28026-28038 (2018).

9. Li, X. S. et al. Gas hydrate formation process for capture of carbon dioxide from fuel gas mixture. Ind. Eng. Chem. Res. 49, 11614-11619 (2010).

10. Li, X. S., Xu, C. G., Chen, Z. Y. \& Cai, J. Synergic effect of cyclopentane and tetra-n-butyl ammonium bromide on hydrate-based carbon dioxide separation from fuel gas mixture by measurements of gas uptake and X-ray diffraction patterns. Int. J. Hydrogen Energ. 37, 720-727 (2012).

11. Linga, P., Kumar, R. N. \& Englezos, P. Gas hydrate formation from hydrogen/carbon dioxide and nitrogen/carbon dioxide gas mixtures. Chem. Eng. Sci. 62, 4268-4276 (2007).

12. Holzammer, C., Schicks, J. M., Will, S. \& Braeuer, A. S. Influence of sodium chloride on the formation and dissociation behavior of $\mathrm{CO}_{2}$ gas hydrates. J. Phys. Chem. B 121, 8330-8337 (2017).

13. Song, B., Nguyen, A. H. \& Molinero, V. Can guest occupancy in binary clathrate hydrates be tuned through control of the growth temperature?. J Phys. Chem. C 118, 23022-23031 (2014).

14. Zhou, X. B., Long, Z., Tang, C. P. \& Liang, D. Q. Kinetic measurements on $\mathrm{CO}_{2}$ hydrate formation in the presence of tetra-n-butyl ammonium bromide. Energ. Fuel 32, 9683-9691 (2018).

15. Hashimoto, S., Murayama, S., Sugahara, T., Sato, H. \& Ohgaki, K. Thermodynamic and Raman spectroscopic studies on $\mathrm{H}-2+$ tetrahydrofuran plus water and $\mathrm{H}_{2}+$ tetra-n-butyl ammonium bromide plus water mixtures containing gas hydrates. Chem. Eng. Sci. 61, 7884-7888 (2006).

16. Li, X. S. et al. Effects of tetrabutyl-(ammonium/phosphonium) salts on clathrate hydrate capture of $\mathrm{CO}_{2}$ from simulated flue gas. Energy Fuel 26, 2518-2527 (2012).

17. Chazallon, B. \& Pirim, C. Selectivity and $\mathrm{CO}_{2}$ capture efficiency in $\mathrm{CO}_{2}-\mathrm{N}_{2}$ clathrate hydrates investigated by in-situ Raman spectroscopy. Chem. Eng. J. 342, 171-183 (2018).

18. Xu, C. G. et al. Insight into micro-mechanism of hydrate-based methane recovery and carbon dioxide capture from methanecarbon dioxide gas mixtures with thermal characterization. Appl. Energ. 239, 57-69 (2019).

19. Zhang, Z. C., Kusalik, P. G. \& Guo, G. J. Molecular insight into the growth of hydrogen and methane binary hydrates. J. Phys. Chem. C 122, 7771-7778 (2018).

20. Zhang, L. X. et al. Kinetic enhancement of capturing and storing greenhouse gas and volatile organic compound: Micro-mechanism and micro-structure of hydrate growth. Chem. Eng. J. 379, 122357 (2020).

21. Subramanian, S. \& Sloan, E. D. Molecular measurements of methane hydrate formation. Fluid Phase Equilibr. 158, 813-820 (1999).

22. Uchida, T., Okabe, R., Mae, S., Ebinuma, T. \& Narita, H. In situ observations of methane hydrate formation mechanisms by Raman spectroscopy. Ann. NY Acad. Sci. 912, 593-601 (2000).

23. Schicks, J. M. \& Luzi-Helbing, M. Cage occupancy and structural changes during hydrate formation from initial stages to resulting hydrate phase. Spectrochim. Acta A 115, 528-536 (2013).

24. Susilo, R., Moudrakovski, I. L., Ripmeester, J. A. \& Englezos, P. Hydrate kinetics study in the presence of nonaqueous liquid by nuclear magnetic resonance spectroscopy and imaging. J. Phys. Chem. B 110, 25803-25809 (2006).

25. Falenty, A., Salamatin, A. N. \& Kuhs, W. F. Kinetics of $\mathrm{CO}_{2}$ hydrate formation from ice powders: Data summary and modeling extended to low temperatures. J. Phys. Chem. C 117, 8443-8457 (2013).

26. Zhou, X. B. et al. In situ Raman analysis on the dissociation behavior of mixed $\mathrm{CH}_{4}-\mathrm{CO}_{2}$ hydrates. Energ. Fuel 30, 1279-1286 (2016).

27. Lee, H. H. et al. Thermodynamic stability, spectroscopic identification, and gas storage capacity of $\mathrm{CO}_{2}-\mathrm{CH}_{4}-\mathrm{N}_{2}$ mixture gas hydrates: Implications for landfill gas hydrates. Environ. Sci. Technol. 46, 4184-4190 (2012).

28. Wang, Y. et al. Raman spectra study hydrogen bonds network in ice Ih with cooling. Spectrochim. Acta A 220, 117131 (2019).

29. Perakis, F. et al. Vibrational spectroscopy and dynamics of water. Chem. Rev. 116, 7590-7607 (2016).

30. Shi, L., Gruenbaum, S. M. \& Skinner, J. L. Interpretation of IR and Raman line shapes for $\mathrm{H} 2 \mathrm{O}$ and D2O ice Ih. J. Phys. Chem. B 116, 13821-13830 (2012).

31. Li, F. \& Skinner, J. L. Infrared and Raman line shapes for ice Ih. II. $\mathrm{H}_{2} \mathrm{O}$ and $\mathrm{D}_{2} \mathrm{O}$. J. Chem. Phys. 133, 244504 (2010).

32. Shi, L., Skinner, J. L. \& Jansen, T. L. C. Two-dimensional infrared spectroscopy of neat ice I-h. Phys. Chem. Chem. Phys. 18, 3772-3779 (2016).

33. Sloan, E. D. \& Carolyn, C. A. Clathrate Hydrates of Natural Gases 3rd edn. (CRC Press, 2007).

34. Qin, J. F. \& Kuhs, W. F. Quantitative analysis of gas hydrates using Raman spectroscopy. AIChE J. 59, 2155-2167 (2013).

35. Moudrakovski, I. L., Sanchez, A. A., Ratcliffe, C. I. \& Ripmeester, J. A. Nucleation and growth of hydrates on ice surfaces: New insights from Xe-129 NMR experiments with hyperpolarized xenon. J. Phys. Chem. B 105, 12338-12347 (2001).

36. Yi, L. Z., Liang, D. Q., Zhou, X. B. \& Li, D. L. Molecular dynamics simulations for the growth of $\mathrm{CH}_{4}-\mathrm{CO}_{2}$ mixed hydrate. J. Energ. Chem. 23, 747-754 (2014).

37. Salamatin, A. N., Falenty, A., Hansen, T. C. \& Kuhs, W. F. Guest migration revealed in $\mathrm{CO}_{2}$ clathrate hydrates. Energ. Fuel 29, 5681-5691 (2015).

38. Peters, B., Zimmermann, N. E. R., Beckham, G. T., Tester, J. W. \& Trout, B. L. Path sampling calculation of methane diffusivity in natural gas hydrates from a water-vacancy assisted mechanism. J. Am. Chem. Soc. 130, 17342-17350 (2008).

39. Liang, S., Hall, K. W., Laaksonen, A., Zhang, Z. C. \& Kusalik, P. G. Characterizing key features in the formation of ice and gas hydrate systems. Philos. T. R. Soc. A 377, 20180167 (2019).

40. Uchida, T. et al. Kinetics and stability of $\mathrm{CH}_{4}-\mathrm{CO}_{2}$ mixed gas hydrates during formation and long-term storage. ChemPhysChem 6, 646-654 (2005).

\section{Acknowledgements}

This work was supported by the National Natural Science Foundation of China (51706230, 51676197), National Key Research and Development Plan of China (2017YFC0307306), Guangdong Natural Science Foundation (2020A1515010374, 2018B0303110007), Guangdong Special Support Program-Local innovation and entrepreneurship team project (2019BT02L278), Guangdong MEPP Fund (No. GDOE [2019]A39), Pearl River S\&T Nova Program of Guangzhou (No. 201806010114). The authors thank Shijun Liu and Peili Chen for their help in the operation of GC and Raman spectroscopy.

\section{Author contributions}

X. Zhou and D. L. proposed and supervised the entire project and X. Zang and X. Zhou performed the experiments and analysis and X. Zhou and Z. L. wrote the manuscript. All authors reviewed the manuscript. 


\section{Competing interests}

The authors declare no competing interests.

\section{Additional information}

Supplementary Information The online version contains supplementary material available at https://doi.org/ 10.1038/s41598-021-88531-x.

Correspondence and requests for materials should be addressed to D.L.

Reprints and permissions information is available at www.nature.com/reprints.

Publisher's note Springer Nature remains neutral with regard to jurisdictional claims in published maps and institutional affiliations.

(c) (1) Open Access This article is licensed under a Creative Commons Attribution 4.0 International License, which permits use, sharing, adaptation, distribution and reproduction in any medium or format, as long as you give appropriate credit to the original author(s) and the source, provide a link to the Creative Commons licence, and indicate if changes were made. The images or other third party material in this article are included in the article's Creative Commons licence, unless indicated otherwise in a credit line to the material. If material is not included in the article's Creative Commons licence and your intended use is not permitted by statutory regulation or exceeds the permitted use, you will need to obtain permission directly from the copyright holder. To view a copy of this licence, visit http://creativecommons.org/licenses/by/4.0/.

(C) The Author(s) 2021 